\title{
The impact of patient factors on use of antifungal medicines in adults with life-threatening illness: a cross-sectional study in 34 English hospitals
}

\author{
Peter Stephens, ${ }^{1}{ }^{12}$ Karim Chikh, ${ }^{1}$ Hubert Leufkens ${ }^{2}$
}

\begin{abstract}
${ }^{1}$ IMS HEALTH, London, UK ${ }^{2}$ WHO Collaborating Centre for Pharmacoepidemiology and Pharmaceutical Policy Analysis, Utrecht Institute for Pharmaceutical Sciences (UIPS), Utrecht, The Netherlands
\end{abstract}

\section{Correspondence to}

Peter Stephens, IMS HEALTH, 210 Pentonville Road, London, N1 9JY, UK and WHO Collaborating Centre for Pharmacoepidemiology and Pharmaceutical Policy Analysis, Utrecht Institute for Pharmaceutical Sciences (UIPS), Utrecht 3508 TB, The Netherlands; pstephens@uk.imshealth.com

Received 14 April 2014 Revised 30 June 2014 Accepted 15 July 2014 Published Online First 1 August 2014
CrossMark

\section{To cite: Stephens $P$,} Chikh K, Leufkens H. Eur J Hosp Pharm 2015;22: 38-45.

\section{ABSTRACT}

Objectives To describe the use of antifungal medicines in English hospitals in adults with life-limiting illness and to investigate the association between sociodemographic variables and the use of high-cost formulations.

Methods Pseudonymised patient-level information extracted from hospital pharmacy systems in 34 English acute general hospitals was linked to a National Health Service database of diagnoses and procedures. National Information Governance Board for England and Ethics approval was granted. The impact of socio-demographic variables on the use of high-cost formulations was assessed using stepwise logistic regression across 13 disease groups. Hospital guidelines on the use of antifungals were sourced and compared.

Results People with haematological malignancies and unconfirmed infection formed the largest disease group (49.3\%). Fungal infection was confirmed in an additional $12.6 \%$. Guidelines focused on antifungal use in neutropenic patients. No guideline cited patient age, deprivation, gender or ethnicity as independent factors influencing treatment. Fluconazole dominated use $(75 \%$ admissions). Significant associations were found between age, gender, deprivation and ethnicity and the use of high-cost antifungals. However, the direction of that association was not consistent across disease groups. Conclusions This study found widespread use of fluconazole, echoing results of earlier studies across Europe. It also found associations between patient factors and high-cost antifungal use that are not easily explained by disease, comorbidities, contraindications, guidelines or any systematic bias against particular groups of patients. It is clear that the drivers of antifungal therapy in hospital are complex and that antifungal stewardship poses a significant challenge for pharmacy.

\section{INTRODUCTION}

The National Health Service (NHS) Constitution in England states that it will provide 'a comprehensive service, available to all, irrespective of gender, race, disability, age, sexual orientation, religion or belief'. ${ }^{1}$ Public bodies must publish information to demonstrate their compliance at least annually. ${ }^{2}$

Access to the treatment of some life-threatening conditions has, however, been shown to vary by age and deprivation. Older people with cancer, for example, have been shown to be less likely to be given access to a clinical nurse specialist and are said to be less likely to receive standard cancer treatments such as surgery, radiotherapy and chemotherapy. ${ }^{3}$ A survey suggested that 'chronological age alone may be used as a proxy for wider biological factors, resulting in some patients [with cancer], being provided with less intense treatment than might be appropriate'. ${ }^{4}$ More deprived patients are said to be more likely to receive late or no cancer treatment. ${ }^{56}$

Observational studies of the effect of sociodemographic factors on the treatment of lifethreatening conditions can be confounded by patient choice. Not all cancer patients will wish to undergo the surgery or chemotherapy offered, for example, and will refuse treatment. Observational studies cannot take patient choice into account. Observational studies comparing the types of drug administered, on the other hand, are less likely to suffer from such confounding. This is because the decisions to provide and accept treatment have already been made.

This paper describes the use of antifungal treatments in people with life-limiting illnesses. Fungal and mould infections are a significant cause of morbidity and mortality, particularly in immunocompromised patients. Mortality rates can reach up to $60 \%$ for people with acute myelogenous leukaemia (AML) and up to $40 \%$ with severe acute pancreatitis. Mortality from fungal and mould infection is reported to be highest in people with haematopoietic stem cell transplants or bone marrow transplants, together with people being treated for solid tumours or cancers of the blood, and people with solid organ transplants. ${ }^{7}$ Younger people survive better, ${ }^{8-10}$ and women with AML have been found to survive better than men. ${ }^{10}$

Treatment strategies vary depending on whether treatment is empirical, pre-emptive or directed. ${ }^{11}$ Rapid initiation of antifungal treatment is essential and has been shown to reduce mortality. ${ }^{8} 912$ Antifungal stewardship is now deemed to be as critical as antibacterial stewardship. ${ }^{13}$

An earlier study of the use of antifungals in 147 hospitals across Europe by the European Surveillance of Antimicrobial Consumption (ESAC) group in 2008-2009 highlighted variation in the use of antifungals by age. Antifungal use increased up to the age group of 60 to 75 years but decreased in patients $>75$ years, unlike antibacterials. This result was not anticipated by the authors. Older patients, they argued, have a lower level of immunity and are, thus, equally likely to acquire both bacterial and fungal infections. The authors found it surprising that the distribution of both antibacterial and antifungal agents did not follow similar trends across all age groups. ${ }^{14}$ 
This paper describes the use of high-cost and low-cost antifungals in people with life-limiting illness in 34 hospitals in England and discusses the implications of the variations seen.

\section{METHODS}

\section{Data sources: pseudonymised data}

Pseudonymised data were extracted from IMS Health's Hospital Treatment Insights. This is a database that combines hospital pharmacy transactions with the NHS Hospital Episode Statistics (HES) database at patient level in 34 English hospitals for the period January 2010 to October 2012. Hospitals were included if local ethical approval had been granted and extraction of the data was able to be automated. The characteristics of these hospitals are summarised in table 1 . The hospitals are seen to be similar to other NHS hospitals in England in terms of the age and gender of those admitted, and in terms of the proportions of admissions for neoplasms, haematology and infectious disease. Table 1 also suggests that these hospitals also form a relatively homogenous group along these same dimensions. ${ }^{15}$

The HES database contains details of all admissions to NHS hospitals in England and is created from patients' clinical records. Following a patient's discharge from hospital, the patient's records are examined by highly trained coders based at each acute hospital. These coders convert the diagnoses and procedures described by the treating physicians into internationally recognised classifications, for example, the International Classification of Diseases. ${ }^{16}$

Drugs dispensed by a hospital pharmacy are either issued directly to the patient or to the ward where the drug will be used ('ward stock'). Ward stock is not issued together with any patient details and so cannot be linked to the patient's records in the HES database. Discussions with pharmacists indicate that both high-cost and low-cost antifungal drugs are kept as ward stock, particularly on haematology wards. It is not likely, however, that use of ward stock will have varied by any of the socio-demographic variables of interest. It is unlikely, for example, that age makes the use of ward stock more or less likely. Systematic error thus seems unlikely.

Moreover, the extent of ward stock use, and thus the impact on the results of this study, can be estimated by comparing the total volumes dispensed with the total volume that is able to be linked to patients. Analysis across the range of molecules included in this study showed that the median percentage able to be linked to a patient was $88 \%$, with fluconazole being the lowest at $60 \%$. This study thus also reflects the use of the majority of antifungal use.

Deidentification is carried out by the Health and Social Care Information Centre before release of the data to IMS Health. The database is approved by the National Information Governance Board and by the National Research Ethics Service Committee South West-Central Bristol Research and Ethics Committee. Approval for the collection of data on an ongoing basis is also granted by each hospital involved.

Data relate to January 2010 to October 2012. Not all hospitals were able to provide data for all months. Data were available for $89 \%$ of months across all hospitals and analysis was restricted to those months where data were available.

\section{Data sources: guidelines}

Regulatory constraints prevent the identification of individual hospitals within the database and so guidelines specific to the hospitals included in this study could not be sourced. Some NHS hospitals publish their management guidelines for antifungal prophylaxis and treatment; however, thirteen hospital guidelines were found and analysed, with some hospitals publishing more than one, these relating to different patient populations. ${ }^{17-30}$ These guidelines were also compared with the guidelines of the European Conference on Infections in Leukaemia published in $2009 .^{31}$

\section{Participants and unit of analysis}

Only records of adults were included in the study. Age is banded into groups prior to receipt of the data by IMS Health in order to help preserve patient confidentiality. This study included only those aged over 22 years of age.

The unit of analysis used in this study was the period during which the patient was in hospital ('admission'). In England, the period of time under the care of a particular consultant in a hospital is known as an 'episode'. If care is transferred from one consultant to another within the same hospital, then a new episode starts, and the combination of these episodes is known as a 'spell'. If the patient is later transferred to another hospital, but the difference between the end of care in one hospital and the beginning of care in another is shown as $<2$ days in the HES database, then the period of care across the two hospitals is known as a 'super-spell'. In this study, the 'admission' is the same as the 'super-spell'.

If a patient was found to have been admitted more than once in the study period, then each of those admissions would be entered separately into the study. Drugs were linked to an admission if the date of dispensing of the drug to that patient fell on or between the start and end date of the admission.

\section{Disease: classification and exclusions}

Records showing antifungal use were grouped according to one of 14 disease groups (figure 1). Group 14 ('other') was excluded from the study, this consisting of a heterogeneous group of different indications, the vast majority of which were not thought to be life-threatening.

People were assigned to groups in a sequential fashion. For example, people assigned to the first group (invasive aspergillosis) could not appear in any other group. The number of patients with a record of HIV/AIDS was very small, and all of these were assigned to other groups earlier in the classification sequence.

Records were assigned to the solid organ transplant group if there was a record of a solid organ transplant at any point from April 2005 (the earliest date for which a date of transplant was available). This is because fungal infections associated with transplants are reported up to more than 5 years after the actual transplant date. ${ }^{10}$ All other records were assigned to a particular disease group only if there was a record of antifungal use and of that disease within that admission.

Diseases were categorised according to the likelihood of the patient receiving antifungal therapy as prophylaxis, treatment or both. Hospital guidelines indicate that antifungal prophylaxis should always be given to those at high risk of fungal infection, notably those undergoing stem cell transplant, those undergoing treatment for acute myeloid leukaemia, aplastic anaemia, myelodysplastic syndrome or acute lymphoblastic leukaemia. ${ }^{17-30}$ A survey of lung transplant centres across Europe and the USA also revealed that antifungal prophylaxis is invariably given, sometimes in combination. ${ }^{32}$ In addition, it is almost certain that those with a confirmed diagnosis of fungal infection will have received treatment. Thus in terms of this study, those with confirmed aspergillosis, candidosis or other fungal infections will almost certainly have received treatment (in addition to prophylaxis potentially) and those undergoing stem cell transplants or lung transplants will almost certainly have received prophylaxis (in addition to 


\section{Original article}

Table 1 Characteristics of hospitals $(n=34)$

\begin{tabular}{|c|c|c|c|c|c|c|c|}
\hline & \multirow[b]{2}{*}{$\%$ Episodes } & \multicolumn{6}{|c|}{$\%$ Of all admissions in England 2011-2012 } \\
\hline & & $\%$ Male & $\%$ Female & $\%>60$ years old & $\%$ Neoplasms & $\begin{array}{l}\% \text { Clinical } \\
\text { haematology }\end{array}$ & $\begin{array}{l}\% \\
\text { Infectious } \\
\text { disease }\end{array}$ \\
\hline $\begin{array}{l}\text { Sample } \\
\text { hospitals }\end{array}$ & $21 \%$ & $20 \%$ & $20 \%$ & $22 \%$ & $20 \%$ & $19 \%$ & $21 \%$ \\
\hline \multirow{3}{*}{$\begin{array}{l}\text { All other } \\
\text { hospital } \\
\text { providers } \\
\text { in } \\
\text { England } \\
\end{array}$} & $79 \%$ & $80 \%$ & $80 \%$ & $78 \%$ & $80 \%$ & $81 \%$ & $79 \%$ \\
\hline & & \multicolumn{4}{|c|}{ Admissions 2011-2012 } & & \\
\hline & Episodes (mean, IQR)* & $\begin{array}{l}\% \text { male } \\
\text { (mean, IQR)* }\end{array}$ & $\begin{array}{l}\%>60 \text { years old } \\
\text { (mean, IQR)* }\end{array}$ & $\begin{array}{l}\text { \% Neoplasm (mean, } \\
\text { IQR)* }\end{array}$ & $\begin{array}{l}\% \text { Clinical haematology } \\
\text { (mean, IQR)* }\end{array}$ & & \\
\hline $\begin{array}{l}\text { Sample } \\
\text { hospitals }\end{array}$ & $210000(50000)$ & $44 \%(3 \%)$ & $47 \%(8 \%)$ & $9 \%(5 \%)$ & $2 \%(3 \%)$ & & \\
\hline
\end{tabular}

treatment if fungal infection was suspected). Other disease groups cannot be grouped in this way.

\section{Drugs administered: classifications and exclusions}

The definition of high-cost antifungals is provided by the NHS. ${ }^{33}$ It includes voriconazole, liposomal amphotericin B, anidulafungin, caspofungin and posaconazole. In addition, micafungin was included by the NHS in Band 1 from 2010/2011.

Low-cost antifungals are defined as conventional amphotericin $\mathrm{B}$, fluconazole, itraconazole and flucytosine and micafungin prior to 2010/2011. Fluctyosine was excluded from the study as it is rarely used, and then only in combination with other low-cost antifungals.

\section{Quantitative variables and statistical analysis}

The dependent variable was the presence or absence of use of a high-cost antifungal. The effect of each socio-demographic variable (age, gender, ethnicity or deprivation) on the dependent variable was investigated using binomial stepwise logistic regression. Age was grouped into bands, the Index of Multiple Deprivation (IMD) into deciles. IMD is an index of multiple deprivation experienced by people living in an area. It attempts

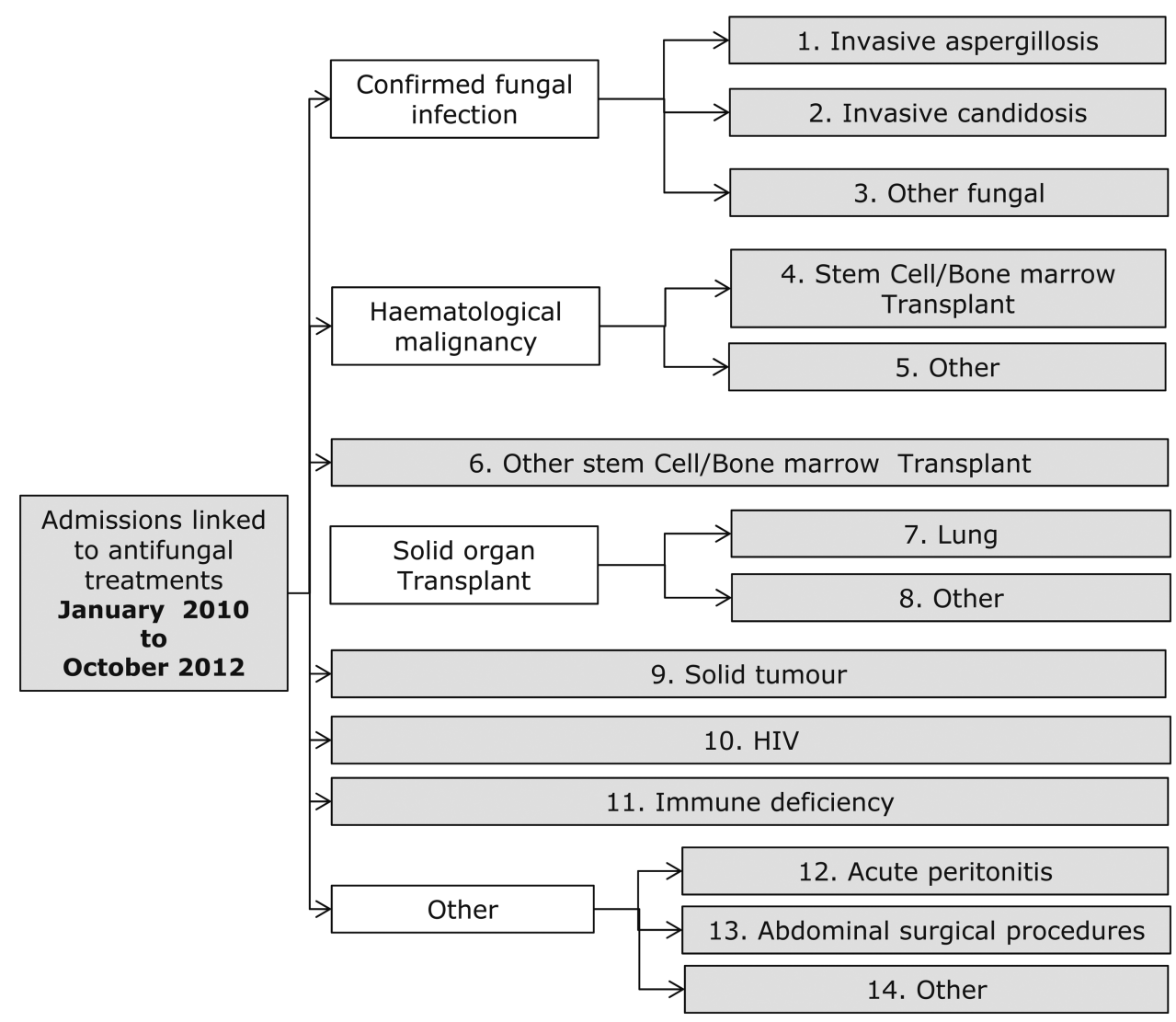

Figure 1 Classification of diseases. 
to measure deprivation along several distinct dimensionsincome, employment, health, education, housing and services, environment and crime, the index being a composite score derived from these. ${ }^{34}$ Age and IMD were treated as ordinal variables within the logistic regression, gender and ethnicity as cardinal variables.

The logistic regression was carried out using the statistical package R V.2.14.0 (31 October 2011).

\section{RESULTS}

Table 2 shows that, by and large, the available NHS guidelines focus on treatment with antifungals in the neutropenic patient. In most cases, the guidelines recommend high-cost treatments for both prophylaxis and treatment. A guideline also points out that liposomal amphotericin B should be avoided in people with renal impairment, voriconazole in people with liver impairment, that caspofungin requires dosage adjustment in people with liver impairment and levels of itraconazole should be monitored weekly. ${ }^{30}$ It should be noted that none of the guidelines suggest that treatment should differ according to age, gender or deprivation.

Table 3 shows the characteristics of patients entered into the study. Both liver and renal impairment were notably higher in people with acute peritonitis or undergoing solid organ transplants (excluding lung), or major abdominal surgery. The definition of renal impairment is restricted to renal failure, as other degrees of impairment are not defined in the HES database. The recorded rate of renal impairment may therefore underestimate the actual number of people with sufficient renal impairment to affect choice of treatment.

Table 4 shows that fungal infection was confirmed in $12.6 \%$ of the admissions included in this study, the predominant pathogen being Candida. Forty-nine per cent of the admissions related to people with haematological malignancy, with a further 33\% relating to people with solid tumours. Fluconazole and itraconazole dominate usage, with high-cost antifungals being more commonly used in confirmed aspergillosis and in people with lung transplant and haematological malignancies (table 2). Prophylactic use could not be distinguished from treatment in the pharmacy record.

The results of the logistic regression for the patient factors are shown in table 5. These results are based on a total of 29973 admissions, 237 having been excluded from the logistic regression due to unknown age and/or deprivation. Certain disease groups also contained too few patients on whom to conduct a logistic regression. The remaining diseases are categorised according to the likelihood of prophylaxis or treatment having been given. Overall increasing age and ethnicity (black) appeared to be negatively associated with use of a high-cost antifungal. Analysis within disease group, however, shows a lack of consistency. In three disease groups, increasing age is negatively associated with use of a high-cost antifungal but in two, confirmed aspergillosis and solid tumours, increasing age is positively associated with use of a high-cost antifungal. At a disease level, the effect of deprivation also appears to be significant, but again the direction of that association is not consistent.

\section{DISCUSSION}

NHS guidelines for the use of antifungal therapy in the neutropenic patient recommend the use of high-cost antifungals in the majority of cases. This recommendation reflects European guidelines. The ELIC-3 guidelines 'strongly recommend' the use of liposomal amphotericin B and caspofungin and 'generally recommend' the use of other formulations of amphotericin, micafungin, voriconazole and itraconazole in people with leukaemia. Fluconazole is not recommended in either the NHS or European guidelines. Indeed, in the ELIC-3 guidelines, fluconazole is described only as an option, it being categorised as having either insufficient evidence for efficacy or with efficacy that does not outweigh possible adverse consequences. ${ }^{31}$

It is surprising, therefore, that in this study fluconazole is found to be the most widely used antifungal, even in those with haematological malignancies, the largest group in the study. Fluconazole was, however, also found to be the most commonly used antifungal across the 147 hospitals in the ESAC study and, in addition, fluconazole constituted $58 \%$ of antifungal use within a study carried out in a tertiary centre in Spain. ${ }^{35}$ In the ESAC study, the authors commented that 'the use of empiric fluconazole in intensive-care units in adults with risk factors for invasive candidiasis is widely practised despite the fact that it is not clearly proven to improve outcome compared with placebo. ${ }^{14}$ In the review of use of antifungals in the tertiary centre in Spain, the authors found that the most common reason for inappropriate use of fluconazole was its prescription for mild oral or vaginal infections that could have been treated with topical antifungal agents. Both the ESAC authors, and

Table 2 Descriptive analysis of guidelines on the use of antifungals in life-limiting disease $\left({ }^{17-30}\right)$

\begin{tabular}{|c|c|c|c|}
\hline & Number of guidelines & Antifungal agents mentioned & $\%$ High cost* \\
\hline \multicolumn{4}{|l|}{ Confirmed infection } \\
\hline Aspergillosis & 9 & Liposomal amphotericin B (7), voriconazole (9), posaconazole (1), caspofungin (1) & 100 \\
\hline Candidosis_-haematology & 4 & Liposomal amphotericin B (2), caspofungin (3), micafungin (1), fluconazole (1) $\dagger$ & 71 \\
\hline Candidosis—non-haematology & 2 & Liposomal amphotericin B (2), caspofungin (1), micafungin (1), fluconazole (1) $\dagger$ & 60 \\
\hline \multicolumn{4}{|l|}{ Empiric treatment } \\
\hline 1st line-haematology & 8 & Liposomal amphotericin B (4), voriconazole (3), amphotericin B lipid complex (1) & 88 \\
\hline 2nd line-haematology & & Caspofungin (4), voriconazole (2), liposomal amphotericin B (1), micafungin (1) & 88 \\
\hline 3rd line-haematology & & Liposomal amphotericin B (1) & \\
\hline Intensive care & 1 & Liposomal amphotericin B (1), micafungin (1), fluconazole (1) & \\
\hline \multicolumn{4}{|l|}{ Prophylaxis } \\
\hline Haematology & 11 & $\begin{array}{l}\text { Posaconazole (7), itraconazole (4), liposomal amphotericin B (4), } \\
\text { voriconazole (2), fluconazole (1) }\end{array}$ & 72 \\
\hline
\end{tabular}


Table 3 Baseline characteristics

\begin{tabular}{|c|c|c|c|c|c|c|c|c|c|c|}
\hline Disease & $\begin{array}{l}\text { Patients } \\
\text { (number) }\end{array}$ & $\begin{array}{l}\text { Admissions } \\
\text { (number) }\end{array}$ & $\begin{array}{l}\% \\
\text { Male }\end{array}$ & $\begin{array}{l}\% \\
\text { British } \\
\text { (white) }\end{array}$ & $\begin{array}{l}\% \\
>68 \text { years } \\
\text { old }\end{array}$ & $\begin{array}{l}\% \text { least } \\
\text { deprived }\end{array}$ & $\begin{array}{l}\% \text { most } \\
\text { deprived }\end{array}$ & $\begin{array}{l}\% \text { Liver } \\
\text { disease* }\end{array}$ & $\begin{array}{l}\% \text { Liver } \\
\text { disease }\end{array}$ & $\begin{array}{l}\% \text { Renal } \\
\text { impairment } \ddagger\end{array}$ \\
\hline 1. Aspergillosis & 457 & 845 & 56 & 88 & 36 & 18 & 28 & $\S$ & $\S$ & 8 \\
\hline 2. Candidosis & 2577 & 2936 & 52 & 87 & 57 & 17 & 24 & 1 & 2 & 16 \\
\hline 3. Other confirmed fungal infection & 13 & 19 & 77 & 54 & $\S$ & $\S$ & $\S$ & 0 & 0 & $\S$ \\
\hline $\begin{array}{l}\text { 4. Stem cell/bone marrow transplant } \\
\text { in haematological malignancy }\end{array}$ & 433 & 440 & 65 & 90 & 9 & 17 & 18 & 0 & 0 & 5 \\
\hline 5. Haematological malignancy & 5326 & 14361 & 59 & 84 & 48 & 25 & 17 & 1 & 1 & 5 \\
\hline $\begin{array}{l}\text { 6. Stem cell/bone marrow transplant } \\
\text { (no record of haematological } \\
\text { malignancy) }\end{array}$ & 26 & 29 & 58 & 73 & 0 & $\S$ & 27 & 0 & 0 & 0 \\
\hline 7. Lung transplant & 96 & 294 & 55 & 96 & $\S$ & 15 & 23 & $\S$ & $\S$ & 15 \\
\hline 8. Other solid organ transplant & 159 & 255 & 55 & 89 & $\S$ & 18 & 27 & 11 & 15 & 34 \\
\hline 9. Solid tumour & 6672 & 9920 & 46 & 89 & 42 & 18 & 25 & $\S$ & 1 & 8 \\
\hline 11. Immunosystem disease & 108 & 126 & 47 & 74 & 34 & 11 & 28 & $\S$ & $\S$ & 16 \\
\hline 12. Acute peritonitis & 294 & 331 & 47 & 86 & 33 & 17 & 30 & 5 & 9 & 24 \\
\hline 13. Abdominal surgery & 450 & 464 & 53 & 85 & 30 & 13 & 35 & 5 & 12 & 26 \\
\hline Total & 16611 & 30020 & & & & & & & & \\
\hline
\end{tabular}

${ }^{*}$ Defined as a record of hepatic failure, not elsewhere classified (ICD10 K72).

tDefined as a record of hepatic failure, not elsewhere classified (ICD10 K72) or a note of toxic liver disease (K71), chronic hepatitis, not elsewhere classified, fibrosis (K73) or cirrhosis of liver (K74).

‡Defined as acute renal failure (N17), chronic renal failure (N18), unspecified renal failure (N19).

$\S S$ mall numbers are suppressed. Some patients can appear in more than one disease category if they were admitted more than once.

indeed the ELIC-3 guidelines, also indicate that widespread use of fluconazole could lead to a rise in the prevalence of resistant fungi. ${ }^{14}{ }^{31}$ For all these reasons, therefore, the apparent high use of fluconazole in this study is worthy of further investigation.

This study found a negative association between increasing age and the use of a high-cost antifungal overall. None of the
NHS guidelines, however, make any reference to age being a factor in treatment choice, and the direction of the association between age and use of an antifungal was not consistent across disease groups. It seems unlikely, therefore, that there is any systematic bias against the elderly in the choice of treatment but, as described below, it is interesting to note that there would appear to be no simple explanation for the results seen in this study.

Table 4 Antifungal use as a proportion of admissions ( $n=30020)$

\begin{tabular}{|c|c|c|c|c|c|c|c|c|c|}
\hline Disease & $\begin{array}{l}\text { Amphotericin } \\
\text { B (\%) }\end{array}$ & $\begin{array}{l}\text { Andulafungin } \\
(\%)\end{array}$ & $\begin{array}{l}\text { Caspofungin } \\
(\%)\end{array}$ & $\begin{array}{l}\text { Fluconazole } \\
(\%)\end{array}$ & $\begin{array}{l}\text { Itraconazole } \\
(\%)\end{array}$ & $\begin{array}{l}\text { Liposomal } \\
\text { amphotericin } \\
\text { B (\%) }\end{array}$ & $\begin{array}{l}\text { Micafungin } \\
(\%)\end{array}$ & $\begin{array}{l}\text { Posaconazole } \\
\text { (\%) }\end{array}$ & $\begin{array}{l}\text { Voriconazole } \\
(\%)\end{array}$ \\
\hline 1. Aspergillosis & 2 & * & 10 & 6 & 37 & 22 & 5 & 7 & 33 \\
\hline 2. Candidosis & 0 & 0 & 8 & 89 & 1 & 4 & 1 & * & 2 \\
\hline $\begin{array}{l}\text { 3. Other confirmed fungal } \\
\text { infection }\end{array}$ & * & * & * & * & 0 & 89 & & * & * \\
\hline $\begin{array}{l}\text { 4. Stem cell/bone marrow } \\
\text { transplant in haematological } \\
\text { malignancy }\end{array}$ & & & 15 & 56 & 33 & 11 & & 4 & 6 \\
\hline $\begin{array}{l}\text { 5. Haematological } \\
\text { malignancy }\end{array}$ & 0 & * & 5 & 71 & 17 & 7 & * & 3 & 5 \\
\hline $\begin{array}{l}\text { 6. Stem cell/bone marrow } \\
\text { transplant } \\
\text { (no record of haematological } \\
\text { malignancy) }\end{array}$ & & & * & * & 55 & * & * & * & 7 \\
\hline 7. Lung transplant & 11 & & 10 & 41 & 28 & 10 & 7 & 4 & 16 \\
\hline $\begin{array}{l}\text { 8. Other solid organ } \\
\text { transplant }\end{array}$ & & * & 7 & 84 & * & * & 4 & * & 7 \\
\hline 9. Solid tumour & 0 & 0 & 2 & 97 & 1 & 1 & 0 & * & 0 \\
\hline 11. Immunosystem disease & * & & * & 82 & 8 & * & & * & * \\
\hline 12. Acute peritonitis & & * & 18 & 80 & * & 5 & 3 & & * \\
\hline 13. Abdominal surgery & & * & 11 & 88 & * & 2 & * & & * \\
\hline Total & 0 & 0 & 4 & 75 & 10 & 5 & 0 & 2 & 4 \\
\hline
\end{tabular}

${ }^{*}$ Small numbers are suppressed. 
Table 5 Results of logistic regression for patient factors

\begin{tabular}{|c|c|c|c|c|}
\hline & Age (older) & Gender (male) & Deprivation (more) & Ethnicity \\
\hline \multicolumn{5}{|l|}{ Overall } \\
\hline All diseases* & $\begin{array}{l}\mathrm{p}<0.001 \\
\text { OR } 0.87(0.86-0.88)\end{array}$ & & & $\begin{array}{l}\text { Black: } p=0.00075 \\
\text { OR } 0.61(0.46-0.81)\end{array}$ \\
\hline \multicolumn{5}{|c|}{ Disease where guidelines indicate treatment with high-cost drug on most occasions } \\
\hline 1. Aspergillosis & $\begin{array}{l}\mathrm{p}=0.023 \\
\text { OR } 1.06(1.01-1.11)\end{array}$ & & & \\
\hline 2. Candidosis & $\begin{array}{l}\mathrm{p}<0.0005 \\
\text { OR } 0.85(0.83-0.88)\end{array}$ & & $\begin{array}{l}\mathrm{p}<0.0005 \\
\text { OR } 0.9(0.87-0.94)\end{array}$ & \\
\hline \multicolumn{5}{|l|}{ Disease where guidelines indicate prophylaxis on most occasions } \\
\hline 4. Stem cell/bone marrow transplant in haematological malignancy & $\begin{array}{l}\mathrm{p}<0.0005 \\
\text { OR } 0.82(0.74-0.89)\end{array}$ & & $\begin{array}{l}\mathrm{p}=0.00312 \\
\text { OR } 1.13(1.04-1.23)\end{array}$ & \\
\hline 7. Lung transplant & & $\begin{array}{l}\mathrm{p}<0.0002 \\
\text { OR } 0.38(0.23-0.64)\end{array}$ & $\begin{array}{l}p=0.026 \\
\text { OR } 0.9(0.82-0.99)\end{array}$ & \\
\hline \multicolumn{5}{|c|}{ Disease where guidelines indicate prophylaxis depends on the risk factors present on presentation } \\
\hline 5. Haematological malignancy & $\begin{array}{l}\mathrm{p}<0.0005 \\
\text { OR } 0.82(0.81-0.83)\end{array}$ & & & $\begin{array}{l}\text { Black: } p=0.005 \\
\text { OR } 0.62(0.841-0.86) \\
\text { mixed: } p=0.005 ; \\
\text { OR } 2.44(1.29-4.52)\end{array}$ \\
\hline \multicolumn{5}{|l|}{ 8. Other solid organ transplant } \\
\hline 9. Solid tumour & $\begin{array}{l}\mathrm{p}=0.02 \\
\text { OR } 1.06(1.01-1.11)\end{array}$ & $\begin{array}{l}\mathrm{p}<0.0005 \\
\text { OR } 1.99(1.56-2.55)\end{array}$ & & \\
\hline 11. Immunosystem disease & & & $\begin{array}{l}\mathrm{p}=0.04 \\
\text { OR } 0.8(0.65-0.98)\end{array}$ & \\
\hline \multicolumn{5}{|l|}{ 12. Acute peritonitis } \\
\hline
\end{tabular}

As noted earlier, the ESAC study found that patients over the age of 75 were prescribed relatively less antifungals in hospital than expected, and that fluconazole is sometimes used without there being strong evidence of efficacy. ${ }^{14}$ If this pattern of use were repeated in English hospitals, then it could explain the negative association between increasing age and use of a highcost antifungal found here. Wider use of a fluconazole in younger patients would constrain antifungal choice in the event that empiric treatment was needed. Itraconazole, for example, would not be an option. More high-cost antifungals would therefore be needed to treat younger patients than old. However, fluconazole prophylaxis is highly unlikely in people with haematological malignancy. ${ }^{35}$ And yet it is precisely in this group that we find a negative association between age and use of a high-cost antifungal. Fluconazole prophylaxis cannot therefore explain all the results seen here.

While empiric or prophylactic use of high-cost antifungal treatments is common, microbiological confirmation of an azole-sensitive fungal infection should drive a switch of therapy to fluconazole or itraconazole, both low-cost drugs. ${ }^{35}$ As noted above, wider use of such drugs in the elderly would lead to the negative association between age and the use of high-cost drugs seen in this study. Such a pattern of use would, however, require that microbiological confirmation of infection was more likely in the elderly. Moreover, microbiological confirmation of the infection would also have led to such patients being categorised in the confirmed infection groups, and not in any other group. As such, microbiological confirmation cannot be said to explain all of the results seen in this study. Having said that, it should be noted that microbiological confirmation of infections may be under-recorded in the HES database.

As noted earlier, colonisation by Candida species was the most common cause of inappropriate use of fluconazole in the study of antifungal use in Spain. ${ }^{35}$ Use of fluconazole in leukaemic patients with gastrointestinal colonisation is common, being recorded to be as high as high as $35 \%$ or more. ${ }^{31}$ Potentially rates of suspected Candida colonisation may be higher in the elderly than in the young, or may have been found to be so in this study. However, if this is a driver of the pattern of use seen in this study, then some may argue that such use may still be inappropriate.

Contraindications could also have played a part in the choice of therapy and thus in the nature of the relationship between patient factors and the use of high-cost antifungals. Liposomal amphotericin B and voriconazole, two key high-cost antifungals, are contraindicated in people with renal or liver impairment, respectively. Renal impairment and chronic liver disease are more common in the elderly. ${ }^{36} 37$ The choice of therapies available in the elderly is thus more constrained in the elderly than in the young. Comorbidities may thus lead to a preference for low-cost antifungals in the elderly. A comparison between the patients with confirmed aspergillosis and confirmed candidosis in this study may indicate just such an effect. The rate of recorded renal impairment in those with confirmed aspergillosis is almost half that in those with confirmed candidosis, while the rate of use of high-cost antifungal is relatively higher in the elderly in those with aspergillosis than in those with confirmed candidosis. However, not all high-cost antifungals are contraindicated in people with liver or renal impairment, and liver disease is hardly recorded in the patients with confirmed aspergillosis in this study. Moreover, the highest rates of renal and liver impairment recorded are in those with acute peritonitis or in those who are undergoing solid organ transplants or abdominal surgery. In none of these groups is any significant difference found between the use of high-cost drugs and age. 
This study has a number of limitations. To preserve patient confidentiality, the identity of the hospital is concealed prior to the data being released to IMS. Differences in protocols and/or fungal resistance patterns could not thus be taken into account although analysis of available hospital guidelines indicates a degree of consistency. Also, although an attempt was made to categorise disease groups according to the likelihood of use of prophylaxis and/or treatment, this study was unable to distinguish between use of the drug as prophylaxis or treatment.

This study found widespread use of fluconazole, echoing results of earlier studies across Europe. It also found associations between patient factors and high-cost antifungal use that are not easily explained by disease, comorbidities, contraindications, guidelines or any systematic bias against particular groups of patients. It is clear from this that the drivers of antifungal therapy in hospital are complex and that antifungal stewardship poses a significant challenge for pharmacy.

\section{Key messages}

What is already known on this subject

- Antifungal stewardship is as critical as antibiotic stewardship. Equity of access to medicines is fundamental to the principles of the National Health Service.

- Concerns have been raised with regards to the widespread use of fluconazole in neutropenic patients.

- Antifungals appear to be used relatively less often in people aged over 75 in hospitals.

\section{What this study adds}

- Fluconazole continues to dominate antifungal use in people with life-limiting illness in English hospitals.

- Patterns of antifungal use cannot be simply explained by disease, comorbidities, contraindications, guidelines or systematic bias against particular groups of patients.

- Antifungal stewardship poses a complex challenge for hospital pharmacy.

Contributors PS obtained regulatory approval for the database, wrote and submitted the protocol, conducted the literature search and wrote the first draft. KC extracted the relevant data from the database and conducted the logistic regression. HL reviewed the drafts of the paper.

Competing interests No funding was received for this study. PS and KC are employed by IMS Health. IMS Health and the Medicines and Healthcare Products Regulatory Agency funded the pilot database from which the data used in this study are extracted. This database is now funded by IMS Health alone. IMS Health itself is funded by sales of information services to both industry and governments around the world. The work was carried out as part of a project to provide feedback services to English hospitals. HL receives no direct funding or donations from private parties, including the pharmaceutical industry. Research funding from public private partnerships (Innovative Medicines Initiative and TI Pharma (http://www.TIPharm.nl)) has been accepted under the condition that no company specific product or company-related study is conducted, outside of the submitted work. He has received unrestricted research funding from public sources including The Netherlands Organisation for Health Research and Development, the EU 7th Framework Programme, the Dutch Healthcare Insurance Board, the Dutch Medicines Evaluation Board and the Dutch Ministry of Health, outside of the submitted work.

Provenance and peer review Not commissioned; internally peer reviewed.

Data sharing statement Regulatory approvals constrain access to the pseudonymised database to a restricted number of employees of IMS Health who access the data in a controlled, audited and ISO approved environment where all queries on the database are automatically recorded. Only aggregated data may be released from this environment. Copies of the SQL queries are available.

\section{REFERENCES}

1 NHS Constitution 8th March 2012.

2 Department of Health. Equality information and equality analysis in 2013-the Department as an Employer. 31 January 2013.

3 Macmillan Cancer Support. Cancer services coming of age: learning from the improving cancer treatment assessment and support for older people project. December 2012

4 Department of Health. The impact of patient age on clinical-decision making in oncology. February 2012

5 Lejeune C, Sassi F, Ellis L, et al. Socio-economic disparities in access to treatment and their impact on colorectal cancer survival. Int J Epidemiol 2010;39:710-7.

6 Downing A, Prakash K, Gilthorpe MS, et al. Socioeconomic background in relation to stage at diagnosis, treatment and survival in women with breast cancer. $\mathrm{Br} J$ Cancer 2007;96:836-40.

7 Menzin J, Meyers JL, Friedman M, et al. Mortality, length of hospitalization, and costs associated with invasive fungal infections in high-risk patients. Am J Health Syst Pharm 2009;66:1711-7.

8 Neofytos D, Lu K, Hatfield-Seung A, et al. Epidemiology, outcomes, and risk factors of invasive fungal infections in adult patients with acute myelogenous leukemia after induction chemotherapy. Diagn Microbiol Infect Dis 2013;75: 144-9.

9 Pfaller MA, Castanheira M, Messer SA, et al. Variation in Candida spp. distribution and antifungal resistance rates among bloodstream infection isolates by patient age: report from the SENTRY Antimicrobial Surveillance Program (2008-2009). Diagn Microbiol Infect Dis 2010;68:278-83.

10 Neofytos D, Fishman JA, Horn D, et al. Epidemiology and outcome of invasive fungal infections in solid organ transplant recipients. Transpl Infect Dis 2010;12:220-9.

11 Freemantle N, Tharmanathan P, Herbrecht R. Systematic review and mixed treatment comparison of randomized evidence for empirical, pre-emptive and directed treatment strategies for invasive mould disease. J Antimicrob Chemother 2011;66(Suppl 1):i25-35.

12 Das I, Nightingale P, Patel M, et al. Epidemiology, clinical characteristics, and outcome of candidemia: experience in a tertiary referral center in the UK. Int J Infect Dis 2011;15:e759-63.

13 Meddings C, Patell R, Okoli S. Antifungal stewardship in clinical haematology. Hospital Pharmacy Europe, 73, March/April 2014. http://www.hospitalpharmacyeurope.com/ featured-articles/antifungal-stewardship-clinical-haematology (accessed 21 Jun 2014).

14 Zarb P, Amadeo B, Muller A, et al. ESAC-3 hospital care subproject group. Antifungal therapy in European hospitals: data from the ESAC point-prevalence surveys 2008 and 2009. Clin Microbiol Infect 2012;18:E389-95.

15 Authors' analysis of: The Health and Social Care Information Centre. Provider leve analysis for HES admitted patient care 2010-11 and 2011-12. http://www.hscic. gov.uk/catalogue/PUB08288 (accessed 21 Jun 2014).

$16 \mathrm{http}: / /$ www.hscic.gov.uk/hes (accessed Apr 2014).

17 Infection Control Committee, Wrightington, Wigan and Leigh NHS Foundation Trust. Management of adults with neutropenia, March 2011.

18 Haematology Department, Royal Devon and Exeter NHS Foundation Trust. Adult Aantifungal prophylaxis in neutropaenia, April 2010.

19 Clinical Haematology Directorate, Nottingham University Hospitals NHS Turst. Clinical guideline for the prophylaxis and treatment of fungal infections in Haematology patients, August 2013.

20 North East Yorkshire and Humber Clinical Alliance (Cancer). Guidelines for the management of infection in adult neutropenic patients. September 2012

21 Hampshire Hospitals NHS Foundation Trust. Empirical prescribing guidelines for systemic fungal infection in adults. February 2013.

22 Gloucester Healthcare NHS Foundation Trust. Empirical/pre-emptive antifungal therapy in adult neutropenic patients. April 2014

23 Medicine Management Committee and Antibiotic Steering Group, Epsom and St Helier University Hospitals NHS Trust. Guidelines for the use of antimicrobial drugs in hospital. February 2013.

24 East Kent University NHS Foundation Trust. Antimicrobial prophylaxis of the immunosuppressed patient. http://www.ekhuft.nhs.uk/staff/clinical/ antimicrobial-guidelines/neutropenia-guidelines/prophylaxis-for-immunosuppressed (accessed 16 Jun 2014).

25 Drug and Therapeutics Committee, Doncaster and Bassetlaw Hospitals NHS Foundation Trust. Antimicrobial management of febrile neutropenic sepsis. January 2013.

26 The Christie NHS Foundation Trust. Guidelines for the management of sepsis (including neutropenic sepsis). May 2013.

27 Arden Cancer Network Executive Group, Arden Cancer Network. Guidelines for the management of invasive fungal infections in adult haematology and oncology patients. June 2010.

28 University Hospital of South Manchester NHS Trust. Guideline for empiric treatment of probable invasive candidosis in AICU and CICU. December 2010.

29 University Hospital of South Manchester NHS Trust. Guideline for treatment of proven mould infections in AICU and CICU. December 2011.

30 Blackpool Teaching Hospitals NHS Foundation Trust. Anti-fungal prophylaxis and treatemnet for haematology patients. February 2012. 
31 Marchetti O, Cordonnier C, Calandra T. Empirical Antifungal Therapy 2009 Update of ECIL-1/ECIL-2 Guidelines. Presented at 3rd Europena Conference on Infections in Leukaemia. http://www.ebmt.org/Contents/Resources/Library/ECIL/Documents/ECIL\% 203\%202009\%20Update\%20Empirical\%20Antifungal\%20Therapy.pdf (accessed 21 Jun 2014).

32 Neoh CF, Snell Gl, Kotsimbos T, et al. Antifungal prophylaxis in lung transplantation-a world-wide survey. Am J Transplant 2011;11:361-6.

33 NHS Connecting for Health. Chemotherapy regimens and high cost drugs. http:/l www.connectingforhealth.nhs.uk/systemsandservices/data/clinicalcoding/ codingstandards/opcs4/chemoregimens (accessed April 2014).
34 Department for Communities and Local Government. The English Indices of Deprivation 2010. Department for Communities and Local Government, 2011.

35 Valerio M, Rodriguez-Gonzalez CG, Muñoz P, et al. COMIC Study Group (Collaborative Group on Mycoses). Evaluation of antifungal use in a tertiary care institution: antifungal stewardship urgently needed. J Antimicrob Chemother 2014;69:1993-9.

$36 \mathrm{O}^{\prime}$ Hare AM1, Choi Al, Bertenthal D, et al. Age affects outcomes in chronic kidney disease. J Am Soc Nephrol 2007:18:2758-65.

37 Frith J, Jones D, Newton JL. Chronic liver disease in an ageing population. Age Ageing 2009;38:11-8 